\title{
Challenges of Environmental Education: Inculcating Behavioural Changes among Indigenous Students
}

\author{
Norshariani Abd Rahman1, Lilia Halim², Abdul Razaq Ahmad², Tuan Mastura Tuan Soh² \\ ${ }^{1}$ Institute of Islam Hadhari, Universiti Kebangsaan Malaysia, Bangi, Malaysia \\ ${ }^{2}$ Faculty of Education, Universiti Kebangsaan Malaysia, Bangi, Malaysia \\ Email:norshariani@ukm.edu.my,lilia@ukm.edu.my,razaq@ukm.edu.my, tuanmastura@ukm.edu.my
}

How to cite this paper: Rahman, N. A., Halim, L., Ahmad, A. R., \& Soh, T. M. T. (2018). Challenges of Environmental Education: Inculcating Behavioural Changes among Indigenous Students. Creative Education, 9, 43-55.

https://doi.org/10.4236/ce.2018.91004

Received: November 21, 2017

Accepted: January 16, 2018

Published: January 19, 2018

Copyright $\odot 2018$ by authors and Scientific Research Publishing Inc. This work is licensed under the Creative Commons Attribution International License (CC BY 4.0).

http://creativecommons.org/licenses/by/4.0/

\begin{abstract}
The purpose of this study was to identify the challenges encountered by teachers in teaching and learning of environmental education and the proposed solutions for cultivating positive behavioural changes among indigenous students. The study was conducted among teachers from 12 primary and secondary indigenous schools in the state of Pahang, Malaysia. This qualitative study used semi-structured interviews to collect data from the teachers. Based on the findings, two challenges in implementing environmental education in indigenous schools were identified: 1) challenges arising from the teachers and 2) challenges from the indigenous students themselves. Teachers were challenged by time constraints, heavy workload, poor teaching aids, unavailability of manual/handbook, and the lack of support from the school administrators. In contrast, the challenges from the indigenous students come from their lack of environmental awareness, hygiene problem, low self-confidence and problem in learning. The identified challenges can be addressed by teacher's competency in integrating environmental education and creative teaching approaches based on the ability of the indigenous students as well as support from the relevant stakeholders.
\end{abstract}

\section{Keywords}

Behaviour, Challenges, Environmental Education, Indigenous Students, Teaching and Learning

\section{Introduction}

The indigenous communities have their own roles in maintaining environmental sustainability which were emphasized in the 1992 Rio de Janeiro Earth Summit 
Conference (UNEP, 2008). This is because these communities are the closest to nature and the natural world as they depend on nature as their main source of economic livelihood (Department of the Indigenous Affairs, 2011; Salleh, 2012; Jelas, Ahmad, \& Ayudin, 2009). Therefore, it is crucial that the indigenous people are educated and given the knowledge to regulate their behaviour to avoid being manipulated or exploited by unscrupulous parties. Due to modernization, the indigenous people have adjusted their lifestyles and experienced behavioural changes. Years ago, they had to tap the abundant natural resources from the forests for their own basic needs. However, due to external demands from various parties and monetary advantages, they are exploited for commercial gains. They are being manipulated in order to commercialise natural resources like medicinal plants as well as exotic animals (Nicholas \& Lasimbang, 2004).

The current generation of indigenous communities is no longer holding on to traditional customs, beliefs and practices which were very much related to the environment (Chopil \& Hunt, 2009). In Malaysia, the indigenous communities were introduced to modern agricultural activities as a result of some development programs, especially through the Resettlement Project (RPS). Thus, they now have new sources of income, especially through the allocation of lands for rubber and oil palm by government agencies, namely the Federal Land Consolidation and Rehabilitation Authority (FELCRA) and Rubber Industry Smallholders Development Authority (RISDA). As a result of this modernisation in agricultural farmland, the indigenous people have left their old farming traditions. Consequently, these modern practices have eroded the traditional transmission of knowledge on environmental management from the older generation to the next generation (Nicholas \& Lasimbang, 2004). Additionally, the loss of traditional culture also hinders them from learning about the environment (Mallen et al., 2009).

The impact of the reduction of knowledge and environmental management transmission from the older to the new generation has caused the youth of the indigenous communities to experience inadequate environmental knowledge. This is supported by a study conducted by Yusuf et al. (2005) which found that the level of environmental knowledge among the indigenous students in seven (7) secondary schools in the district of Pekan, Rompin and Bera, Pahang were low. These findings indirectly reflected the poor environmental education knowledge among the indigenous students. Such a finding is a cause for concern as environmental knowledge is essentially the basis in shaping the attitude and behavioural changes towards environmental protection (Elder, 2003; He et al., 2011).

Awareness and interest of the indigenous students on environmental education were also low as compared to main tribes (Quimby, Seyala, \& Wolfson, 2007). Environmental awareness and interest will affect their behaviour towards environmental conservation (Elder, 2003; Hungerford et al., 2005). A study by Rahman (2010) on the involvement of indigenous communities on the issues re- 
lated to the environment found that their awareness, involvement, and action or participation for better environment were still low and inadequate.

The lack of environmental knowledge, awareness and behaviour among the indigenous students require the intervention of committed teachers to play their role in implementing environmental education at school so that these students' awareness and behaviour towards their environment can be developed. However, constraints that arise in applying environmental education became the reason why most teachers do not apply environmental education in their teaching and learning in schools. Previous research has reported that the major constraints were lack of time (Kim \& Fortner, 2006; Lane et al., 1994; McKeown-Ice, 2000; Shaari, 2009; Pace, 2003; Samuel, 1993; Simmons, 1995), and limited course handbooks and training on environmental education (Kim \& Fortner, 2006; Samuel, 1993; Simmons, 1995). Lack of manuals and courses related to environmental education among teachers has resulted in teachers having low knowledge about environmental education and this has resulted in teachers being incapable of integrating environmental education in their teaching (Samuel, 1993; Lane et al., 1994; Kin, 2004). These constraints have negative implications on the environmental behaviour of the indigenous students. Thus, this study aimed to identify the challenges in inculcating environmental education among indigenous students from the teachers' perspectives. Identification of challenges would help to overcome these challenges in order to inculcate environmental education among the indigenous students.

\section{Literature Review}

In Malaysia, Environmental Education is based on the philosophy and the objective (objectives) of environmental education set by the Ministry of Education Malaysia. In general, the philosophy of Environmental Education involves three components namely; 1 ) adhering to the existence of the environment that forms part of the essential element of nature; 2) knowledge related to the environment needs to be experienced in order to be shared together; and 3) fostering the spirit of love for the environment by talking about ethical, moral and aesthetic values (Ministry of Education, 1998).

The objectives of Environmental Education set by the Ministry of Education (1998) also have similarities with the objectives of the Belgrade Charter and the Tbilisi Declaration (Palmer, 1994, 1998) which are to acquire knowledge, show concern over environmental issues, foster a positive attitude, master the skills in identifying problems in the environment and to engage in solving environmental problems. The ultimate goal of Environmental Education is to produce an environmental citizen (Muda, 2007). An environmental citizen is defined as someone who should be a member of the environmental group or participate in environmental activities, think emotionally about environmental issues and have a personal sense of responsibility towards the resolution of environmental problems. One way to increase the number of environmental citizens is through En- 
vironmental Education.

Environmental education can change a person's beliefs and attitudes towards the environment in a short time but should ultimately affect the person's behaviour in the long time (Gralton, Sinclair, \& Purnell, 2004). Therefore, the Environmental Education curriculum should not only provide important information and practical skills, but must create curiosity and inspire students' interest to enhance the learning experiences (He et al., 2011). Environmental education in Malaysia is divided into two, namely formal and informal environmental education. In formal Environmental Education, the learning process starts from the primary up to the tertiary level. At the primary and secondary levels, Environmental Education is not taught as a separate subject but is included in other subjects across the curriculum (Ministry of Education, 1998). The teaching approach that can be used in formal environmental education includes classroom teaching, out-of-school approach and informal education (Gralton, Sinclair, \& Purnell, 2004). To assist teachers in implementing Environmental Education across the curriculum, the Ministry of Education (MOE) has issued a teacher's guide of the implementation. However, $75 \%$ of the teachers not only did not get the guidebook but did not know the existence of the book (Shaari, 2009). This results in the effort of implementing Environmental Education at the school level by the Ministry of Education to a large extent unaccomplished or unrealized as it does not seem to reach the implementation agent which is the teachers.

Informal environmental education in Malaysia can be classified into two main groups, namely the activities undertaken by the government and activities organised by non-governmental organisations (NGOs) (Chelliah, 1982). Activities carried out by the government are mostly under the Department of Environment (DOE) such as promoting environmental awareness through outdoor activities, environmental theme competitions, Sustainable School or Sekolah Lestari Competition, Environmental Hero (Wira Alam), and Environmental Awareness Camp (KeKAS). It also includes educational materials such as the Green Era book (Buku Era Hijau), brochures, articles, and guidelines on implementing environmental protection and regulations that are distributed freely to government departments, organisations, schools, institutions of higher learning, libraries and many others. DOE also collaborates with the mass media as well as the private sector in promoting environmental awareness. The Ministry of Science, Technology and Innovation (MOSTI) also plays a role in fostering environmental awareness to the public by publishing an estidotmybook with Utusan Malaysia (Department of Environment, 2007).

Environmental education in Malaysia is conducted in a cross curricular framework; therefore, teachers need to be smart in integrating subject matter with environmental education. However, previous studies showed that teachers were actually facing certain constraints in implementing environmental education in schools. The constraints were more on the conceptual barriers (such as lack of understanding of the scope) and content of the environmental education 
(Kin, 2004), logistical barriers (such as time constraint, inadequate teaching materials, inappropriate class size, financial and transportation problems), and issues of security when taking school children out of their settlements (Shaari, 2009), teachers' competencies (Hungerford et al., 2005), and lack of teachers' commitment in environmental education (Ko \& Lee, 2003). Overall, it can be concluded that the constraints in environmental education can be categorised into four factors; 1) conceptual constraint, 2) logistical, 3) teachers' competencies, and 4) commitment (Ham \& Sewing, 1998).

However, the challenges that teachers face in implementing Environmental Education to indigenous students are slightly different from regular schools. Since indigenous students are minorities who have their own language and culture, teachers need to be smart in adapting to the environment of the indigenous community. Moreover, indigenous students also face problems in learning because of language differences. Therefore, teachers need to use pedagogues appropriate to the context of the indigenous students. Biermann (2008) has highlighted three criteria of aboriginal pedagogies in environmental education i.e. experiential-based learning, group-dynamic learning and students-oriented learning. In addition, teachers' competencies in implementing Environmental Education need to be enhanced. The competencies required as an Environmental Education educator are basic knowledge of the environment (ecological knowledge, sociopolitics, local culture and teaching and learning theory), basic skills in applying Environmental Education, and the ability to integrate environmental education into subjects taught (May, 2000). Therefore, providing pre-service professional development on environmental education is one of the solutions to cater to teachers' lack of competence in implementing environmental education at schools.

\section{Research Methodology}

\subsection{Study Context}

This research aimed to explore the challenges encountered by teachers in cultivating environmental care behaviour among indigenous students. This descriptive case study utilised the semi-structured interview method to obtain data from teachers who were teaching indigenous students in primary and secondary schools in the state of Pahang, Malaysia. The schools involved in this study were considered as rural schools.

\subsection{Participant}

Participant determination and selection process was based on the purpose and questions of the study. Thus, purposive sampling was utilised in this study to ensure that participants would be able to provide the information required to answer the research questions (Patton, 2001). The participants were teachers who were teaching at indigenous schools in the state of Pahang. The teachers were selected regardless of their teaching subject because environmental educa- 
tion has to be implemented across the curriculum in Malaysia. Six (6) primary and six (6) secondary school teachers were involved in the study. Purposive sampling method was applied to obtain data from the selected participants. The selection of the participants was based on the willingness of the teachers to be actively involved in the interviews. The respondents were coded as PT1, PT2, PT3, PT4, PT5, and PT6 for the primary school teachers while the respondents who were teachers from the secondary schools were coded as ST1, ST2, ST3, ST4, ST5 and ST6. The respondents varied in terms of their educational background and the subject taught.

\subsection{Data Collection Procedure}

The researcher held preliminary meeting with the participants to explain the purpose of the study and to get their permission to conduct the interview. The researcher then confirmed the date and time of the interview with each of the participants according to the availability of the participants. The researcher began by building rapport with the participants first so that the participants were prepared mentally and physically to provide the information based on the research questions. The researcher also informed the participants that the study required the interviews to be recorded. Therefore, a letter of authorisation and acknowledgment as a participant must be signed voluntarily by the participants. The preparations were made to ensure that all the interviews went well.

\subsection{Data Analysis Procedure}

Data analysis is a critical process in which data were collected through various methods of analysis. All the data in this study were obtained from the semi-structured interviews. After each of the interviews was conducted, the researcher created a transcript of the interview. The verbatim transcript was further analysed manually. The researcher built an open coding for each verbatim transcript and then incorporated the same code into several categories. The process continued until all the themes and sub-themes of the teachers' challenges and how to overcome the challenges of integrating environmental education in the indigenous schools for inculcating environmental care behaviour among the indigenous students were identified and categorised.

\section{Findings}

Based on the interviews, teachers' perspectives were recorded. This study found that the challenges faced by the teachers in implementing environmental education to indigenous students can be categorised into two elements i.e. i) the teachers' constraints and ii) challenges from the indigenous students.

\subsection{Teachers' Constraints}

There were two major constraints perceived by many of the teachers in implementing environmental education; time constraint and being overburdened with 
workload in school.

PT2: "There is no time to bring students out, they study in the classroom only..."

PT4: "time barrier. So we just story to students"

PT1: "Here, the teacher is also a clerk ...so it emerge what is important and not important..."

Based on the demographic background of the participants, only three teachers have tertiary education in environmental education, while none of them have attended in-service course or training on environmental education or any training related to it. This is one of the challenges where the teachers do not know how to plan and integrate environmental education in the subject matter in their teaching.

PT1: "There is no special course, there is a subject of Outdoor Education. That is the recreation, go trekking, kayaking ...during trekking look at plants and the environment..."

PT3: "Outdoor. In the college there is an outdoor education...go to Redang Island... recreation, at the same time learning about the environment... then I go trekking, there's a show of plant trees...”

This situation was worsened by the fact that none of the teachers knew about "The Handbook on Environmental Education across the Curriculum" issued by the Ministry of Education (MOE). This shows that the effort made by the Ministry of Education was ineffective. The manual or handbook for environmental education was not available in the schools, and neither was it in the teachers' personal copy. In fact, all the teachers involved in this study admitted that they did not know about the handbook provided by the Ministry. Thus, without the manual, most of the teachers had to depend on other sources for information on environmental lessons.

ST3: "In terms of materials. Guideline books for teachers".

PT2: “I don't know about the handbook of environmental education by Ministry of Education".

Most of them gathered information through the internet, newspapers, magazines, and electronic media (like television and radio). However, they were also experiencing problems with the internet connection and inadequate internet facilities. In other words, teachers were frustrated with the internet services provided.

PT1: “Internet problem... always loading. Waste time... that's the barrier".

The lack of teaching aids and the ineffective teaching methods would result in classroom lessons that were boring and uninteresting which would not do much in attracting the indigenous students' interest in learning about the environment. In addition, most of the teachers did not use appropriate teaching aids in teaching environmental education. Some teachers reported using only the newspapers and observing the school surroundings to demonstrate environmental issues. 
PT1: "Sometimes at the papers that the students read, show pictures and ask the question why floods happen? What the causes? Why?..."they can look around, just like there have been bald (while point out towards the hill at the edge of the school area). Then, we teach the effect, ask question why... usually relate to their everyday life, so that they can see what happen to themselves..."

PT3: "Look at the picture of Klang river, ask them, is there any difference of this water with water here? Why dirty?"

A few other additional problems were also revealed in this research. It was found that the support from the administration and other stakeholders (such as Department of the Indigenous Affairs, Ministry of Education and universities) were limited. This had contributed to the ineffective teaching of environmental education in the schools. Environmental education is not only dependent on the teachers in the teaching and learning process but also requires the support of other various parties involved, for example by carrying out awareness programmes in the schools for the students. The results showed that these agencies did not come to the schools to be involved in or to organise environmental awareness programmes.

PT1: "there is no outside agency come to school to talking about environmental education..." "Lack of administrator supports..."

\subsection{Challenges from the Indigenous Students}

Based on the teachers' depiction of the scenario in the schools, several additional challenges arose in teaching environmental education to the indigenous students. The students' environmental awareness was very low. Moreover, they do not have confidence in their study, have hygiene problems, and learning problems as well (the indigenous students were always absent from school, suffer from illiteracy and have no interest in the subject). The indigenous students were still lagging behind in education as compared to the other non-indigenous communities. Therefore, the emphasis of the teaching and learning activities were more on the aspects of academic achievement first.

PT5: “Less environmental attitude”.

ST2: "Less concern about environment".

ST5: "Low awareness among indigenous students about environmental education".

PT1: "must advise them every day...in order to make a practice, we must practice every day. Students also have a low confident... They worried if other people said that they are not smart. They feel shy... So that, to develop the confident and awareness take time... that's the challenge".

PT2: “...in the classroom it's a habit for them to tear their own book. Make a mess. That is a habit of him, tearing his own book...meaning that, littering is nothing for them... because they have no religion, there is no guideline".

PT2: "The first thing is cleanliness...students here a bit messy".

ST1: "Students illiterate...school attendance problem and no interest in edu- 
cation".

ST3: "indigenous students always absent in schoop".

\subsection{Recommendations to Overcome Constraints in Integrating Environmental Education from the Teachers' Point of View}

Five elements were highlighted by the interviewed teachers in relation to the ways of overcoming the constraints in the implementation of environmental education, namely 1) the need for guidebooks (PT3, PT4 and PT5), 2) chart facility to put up posters (PT1) and CDs about the environment (PT1), 3) special programmes on the environment (PT3, ST3 and ST5), 4) the support of school administrators (PT1, ST1) and all parties, including parents, Department of Indigenous Development, and Ministry of Education (PT5, PT6, ST1 and ST2), and 5) the need for teachers to constantly motivate and advice the students in caring for the environment (ST4).

PT3: "If can, there are one syllabus or guideline book for teachers in integrating environmental education and what is necessity at indigenous schools".

PT1: "Get a chart like picture frame to paste about environmental education, how to protect the environment...cd".

PT3: "If the environmental education is compulsory, then we do..."

PT1: "We have to submit the proposal for taking students out to administration. If the administrator consider the activity is importance, then they will be verified... because we have collaborated each other".

ST1: "There need to be cooperation between all stakeholders, parents, Department of Indigenous, schools and ministry of education".

ST2: "Efforts from all parties need to be done and not just focus on theories".

ST4: "Always motivate and advise students".

\section{Discussion}

The main constraints faced by the teachers in integrating environmental education were time constraints and being overloaded with school work. These two main problems were also recorded in previous studies (Shaari, 2009), revealing that these were old and continuous challenges faced by teachers. Clearly, the findings indicate that these problems are still unresolved until today. Moreover, the teachers claimed that they did not receive the handbook on environmental education across the curriculum prepared by MOE. Similar findings were recorded by Shaari (2009) who found that 75 percent of teachers were not aware of the existence or the availability of this handbook. The lack of teaching resources requires teachers to be more creative in using available resources as long as the method used can trigger students' interest in their lesson. However, having attractive and impressive teaching aids would help promote and facilitate students' understanding of the subject, allowing students to understand the subject better and faster.

Previous research showed that indigenous students preferred teachers to apply 
fun-learning approaches such as games and singing in their lessons (Mamat et al., 2012). Thus, teachers really need to plan comprehensive teaching strategies to make learning environmental education more fun and enjoyable for the indigenous students. Teachers also need to be skilful in the use of creative teaching approaches (Bodzin et al., 2010); nonetheless, the approaches employed need to be appropriate to the abilities of the indigenous students. The students are living in natural environment, and thus hands-on activities and outdoor learning approaches such as experiments, role playing, simulation, and activity-based learning are suitable and authentic for the indigenous students. Not only will these learning approaches make their learning activities more fun and enjoyable, it will also fit well with their abilities in learning. Additionally, these approaches will provide opportunities for the students to apply and bring what they have learnt in school to real life or their daily life activities which could help develop long lasting environmental care behaviour among the students.

Teaching and learning of environmental education and environmental awareness programmes will become more effective if the environmental science concepts the indigenous students have learnt in school are combined with their indigenous knowledge. Therefore, ethnobiologists should work together with environmentalists to plan and design specific environmental programmes for the indigenous communities, particularly for the indigenous students. This in return will help the community in maintaining their indigenous culture, especially in relation to their environmental culture and traditional environmental management.

Teachers also have to be seriously committed in implementing the environmental education course. Teachers' strong commitment will help in overcoming the constraints and challenges as perceived by the teachers themselves. Hence, the Ministry of Education should provide courses or conduct professional development courses or training in the application of environmental education. Such courses or training will be helpful in guiding the teachers in planning instructional learning of environmental education which is fitting to the culture of the indigenous community. Teachers must also take the initiative to understand the indigenous culture related to the environment to help make the teaching and learning process of environmental education relevant to the indigenous students.

Additionally, school administrators should also play an active role in implementing awareness programmes in school and in consistently promoting environmental conservation programmes and practices (such as recycling, voluntary work (gotong royong), replanting trees, composting waste materials, and trash-picking period before the academic session commences). Administrators must also set aside financial allocations for environmental awareness programmes in school, including taking students for field-trips to increase students' knowledge about environmental issues such as visiting disposal landfills, recycling centres, zoos, and environmental museums and participating in environmental camps. Additionally, students must also be exposed to the skills in investigating environmental issues (Hungerford \& Volk, 1990; Hungerford et al., 
2005).

One of the challenges stemming from indigenous students in this study was cleanliness. This problem has also been reported in other previous studies. Ahmad, Kassim, \& Jelas (2011) found that indigenous students' hygienic awareness and cleanliness practices were very low. Hence, the teachers had to take longer time to foster environmental awareness, particularly in personal hygiene, followed by classroom cleanliness and environmental aspects as a whole. The indigenous students' nature of having low self-esteem, and their lack of confidence also had implications on their behaviour towards the environment. Therefore, environmental care behaviour must be perfected among indigenous students as a common daily practice.

\section{Conclusion}

The natural lives of the indigenous people are inseparably linked to the environment; thus, their action and natural behaviour towards environmental conservation will be value-added in natural resources preservation. However, these indigenous people are also experiencing inevitable changes especially in their lifestyles. The changes are particularly important to the younger generation in relation to environmental care behaviour. Therefore, environmental education in schools is very important. Unfortunately, there are many challenges and constraints faced by teachers in implementing environmental education for indigenous students. The challenges stem from the teachers' constraints and from the indigenous students themselves. These challenges need to be resolved in order to ensure the effectiveness of environmental education in terms of changing the behaviours of the younger generation towards responsible environmental behaviour. For future research, we recommend investigating the competencies of teachers in integrating environmental education in indigenous schools. It is hoped that this research will provide valuable information and guidelines for the stakeholders in planning professional development courses and training for teachers in integrating environmental education, in particular for indigenous students so that teachers can be assisted and helped in tackling the challenges they face effectively.

\section{References}

Ahmad, A. R., Kassim, Z., \& Jelas, Z. M. (2011). Competencies of Social Intelligence among Orang Asli in Malaysia. In Proceeding of International Seminar Education Comparative in Curriculum for Active Learning between Indonesia and Malaysia (519-528). Bandung: Universiti Pendidikan Indonesia.

Biermann, S. (2008). Indigenous Pedagogies and Environmental Education. International Journal of Pedagogies and Learning, 4, 27-38. https://doi.org/10.5172/ijpl.4.3.27

Bodzin, A. M., Klein, B. S., \& Weaver, S. (2010). The Inclusion of Environmental Education in Science Teacher Education. New York: Springer. https://doi.org/10.1007/978-90-481-9222-9

Chelliah, T. (1982). Environmental Education in Malaysia-A Decade Since Stockholm. 
In D. Bandhu, \& N. L. Ramanathan (Eds.), Education for Environmental Planning and Conservation (pp. 57-59). New Delhi: Indian Environmental Society.

Chopil, T. Y., \& Hunt, B. T. W. (2009). Orang Asli and Environment. www.perakspeak.com

Department of Environment (2007). National Environment Policy. http://www.nre.gov.my/en-my/Environment/pages/default.aspx

Department of the Indigenous Affairs (2011). Maklumat Orang Asli. http://www.jakoa.gov.my/org-asli/

Elder, J. L. (2003). A Field Guide to Environmental Literacy: Making Strategic Investment in Environmental Education. North Carolina: Environmental Education Coalition.

Gralton, A., Sinclair, M., \& Purnell, K. (2004). Changes in Attitudes, Beliefs and Behavior: A Critical Review of Research into the Impacts of Environmental Education Initiatives. Australian Journal of Environmental Education, 20, 41-52. https://doi.org/10.1017/S0814062600002196

Ham, S. H., \& Sewing, D. R. (1998). Barriers to Environmental Education. The Journal of Environmental Education, 19, 17-23. https://doi.org/10.1080/00958964.1988.9942751

He, X. E., Hong, T., Liu, L., \& Tiefenbacher, J. (2011). A Comparative Study of Environmental Knowledge, Attitudes and Behaviors among University Students in China. International Research in Geographical and Environmental Education, 20, 91-104. https://doi.org/10.1080/10382046.2011.564783

Hungerford, H. R., \& Volk, T. L. (1990). Changing Learner Behavior through Environmental Education. Journal of Environmental Education, 21, 8-21. https://doi.org/10.1080/00958964.1990.10753743

Hungerford, H. R., Bluhm, W. J., Volk, T. L., \& Ramsey, J. M. (2005). The Tbilisi Declaration. Essential Readings in Environmental Education (3rd ed.). Champaign, IL: Stripes Publishing.

Jelas, Z. M., Ahmad, A. R., \& Ayudin, A. R. (2009). Historology Perspective of the Aboriginal People in the Malaysian Peninsular. In The Indigenous People: Educational and Sociocultural Perspective (pp. 1-18). Bangi: National University of Malaysia.

Kim, C., \& Fortner, R. (2006). Issue-Specific Barriers to Addressing Environmental Issues in the Classroom: An Exploratory Study. Journal of Environmental Education, 37, 15-22. https://doi.org/10.3200/JOEE.37.3.15-22

Kin, C. (2004). Survey of Primary and Secondary School Teacher's Teaching Competencies for Environmental Education in Xicheng District of Beijing. Chinese Education and Society, 37, 39-44.

Ko, A. C., \& Lee J. C. (2003). Teachers' Perceptions of Teaching Environmental Issues within the Science Curriculum: A Hong Kong Perspective. Journal of Sciences Education and Technology, 12, 187-204. https://doi.org/10.1023/A:1025094122118

Lane, J., Wilke, R., Champeau, R., \& Sivek, D. (1994). Environmental Education in Wisconsin: A Teacher Survey. The Journal of Environmental Education, 25, 9-17. https://doi.org/10.1080/00958964.1994.9941959

Mallen, I. R., Barrazab, L., Bodenhornc, B., \& Garcia, V. R. (2009). School and Local Environmental Knowledge, What Are the Links? A Case Study among Indigenous Adolescents in Oaxaca, Mexico. International Research in Geographical and Environmental Education, 18, 82-96.

Mamat, W. H., Ahmad, A. R., Abdullah, R., \& Seman, A. A. (2012). Students; Perspective of Schools and Education. In Proceeding of International Conference of Education Comparative in Competency Based Curriculum between Indonesia and Malaysia (pp. 419-434). 
Bandung: Universiti Pendidikan Indonesia.

May, T. S. (2000). Elements of Success in Environmental Education through Practitioner Eyes. Journal of Environmental Education, 31, 4-11. https://doi.org/10.1080/00958960009598639

McKeown-Ice, R. (2000). Environmental Education the United States. A Survey of Preservice Teacher Education Programs. Journal of Environmental Education, 32, 4-11. https://doi.org/10.1080/00958960009598666

Ministry of Education (1998). Handbook of Environmental Education across the Curriculum for Teachers. Kuala Lumpur: Development of Curriculum.

Muda, A. (2007). Who Is an Environmental Citizen? Era hijaukearahgenerasilestari, 4, JabatanAlamSekitar Malaysia.

Nicholas, C., \& Lasimbang, J. (2004). Biodiversity \& Indigenous Knowledge System in Malaysia. Subang Jaya: Center for Indigenous Concern.

Pace, P. J. (2003). Environmental Education: Providing a Context for a Meaningful Science Education. Journal of Baltic Science Education, 1, 28-35.

Palmer, J. A. (1998). History and Development of Environmental Education. In Environment Education in the 21st Century. Theory, Practice, Progress and Promise (pp. 3-24). London: New Fatter Lane.

Palmer, J., \& Neal, P. (1994). The Handbook of Environmental Education. London: New Fatter Lane.

Patton, M. Q. (2001). Qualitative Research and Evaluation Methods (3rd ed.). Thousand Oak, CA: Sage.

Quimby, J. L., Seyala, N. D., \& Wolfson, J. L. (2007). Social Cognitive Predictors of Interest in Environmental Science: Recommendations for Environmental Educators. The Journal of Environmental Education, 38, 43-52. https://doi.org/10.3200/JOEE.38.3.43-52

Rahman, H. A. (2010). The Involvement of the Native People in Environmental Issues: A Survey on the Mah Meri Tribe in Carey Island, Kuala Langat, Selangor. Human Science Journal, 17, 114-134.

Salleh, H. (2012). Establishing Researches on the Malaysian Indigenous People. Inaugural Lecture Tun Sri Lanang Library, National University of Malaysia, Bangi: National University of Malaysia Press.

Samuel, H. R. (1993). Impediments to Implementing Environmental Education. The Journal of Environmental Education, 25, 26-29. https://doi.org/10.1080/00958964.1993.9941941

Shaari, M. Z. A. (2009). Integrating Environmental Education in Geography Teaching in Secondary School: Knowledge, Attitude, Efficacy and Practices. Unpublished Doctorate Thesis, Bangi: The National University of Malaysia.

Simmons, D. (1995). Developing a Framework for National Environmental Education Standards. In Papers on the Development of Environmental Education Standards (pp. 10-58). Troy, OH: NAAEE.

United Nations Environmental Programme (UNEP) (2008). Indigenous Knowledge in Disaster Management in Africa. http://africanclimate.net/sites/defaults/files/indigenous\%20Booklet\%20UNEP.PDF

Yusuf, N., Ibrahim, N. I., Sulaiman, R., \& Mamat, R. (2005). Environmental Knowledge and Awareness among the Aboriginal Students. In Proceeding of Managing the Environment National Seminar (pp. 221-239). Bangi: National University of Malaysia. 